\title{
Constituents of Helenium amarum (Compositae). I. X-Ray Crystallographic Determination of Heleniamarin, a New Sesquiterpene Lactone
}

TOR OTTERSEN, ${ }^{a}$ ULLA SøRENSEN, $^{a *}$ MAHMOUD A. ELSOHLY ${ }^{\mathrm{b}}$ and CARLTON E. TURNER ${ }^{\mathrm{b}}$

a Department of Chemistry, University of Oslo, Oslo 3, Norway and b Research Institute of Pharmaceutical Sciences, School of Pharmacy, University of Mississippi, University, Mississippi 38677, U.S.A.

The structure of heleniamarin, $\mathrm{C}_{17} \mathrm{H}_{22} \mathrm{O}_{5}$, a compound isolated from Helenium amarum, has been determined using 1900 reflections above background level collected at $-165^{\circ} \mathrm{C}$. The compound was found to be: $2 a, 4 a, 5,6,8$,$9 a, 9 b, 9 c-o c t a h y d r o-2$-hydroxy-2,2a,6,9a-tetramethyl-2H-1,4-dioxadicyclopent [cd,f]azulene3,9 -dione $(1$, the crystallographic numbering is indicated), closely related to the antitumor agent tenulin (2), which previously has been isolated from the same plant." Heleniamarin crystallizes in the space group $P 2$ with cell dimensions $\left(t=-165^{\circ} \mathrm{C}\right): a=8.843(8) \AA, b=$ $7.991(7) \AA, c=10.938(10) \AA, \beta=96.41^{\circ}(7)$.

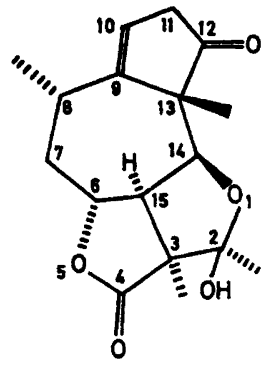

1

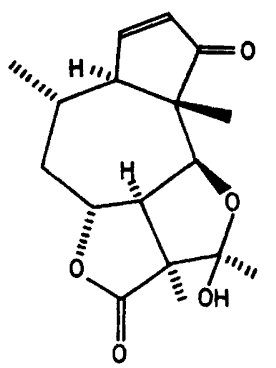

2
The structure model was refined to an $R$ of 0.057 and a weighted $R$ of 0.052 . Estimated standard deviations in bond lengths and bond angles are $0.005 \AA$ and $0.3^{\circ}$, respectively. The central seven-membered ring has a chair conformation with the five atoms in positions $7,8,13,14$ and 15 forming a plane. Both the

* On leave from: Department of General and Organic Chemistry, University of Copenhagen, The H. C. Ørsted Institute, DK-2100 Copenhagen, Denmark.

Aeta Chem. Seand. B 32 (1978) No. 2 cyclopentene and the furan ring have envelope conformations with the $11(0.319 \AA)$ and 3 $(0.578 \AA)$ atoms, respectively, out of the ring planes. The lactone ring has a twist conformation with the 6 atom $0.266 \AA$ above and the 15 atom $0.250 \AA$ below the plane of the other three ring atoms. The major plane of the cyclopentene ring forms an extension to the chair conformation of the seven-membered ring. The lactone and furan ring form an approximate $V$ around their central $3-15$ bond. The torsional angles $14-15-3-4$ and $6-15-3-2$ are $150.0(3)$ and $-89.9(3)^{\circ}$, respectively, with $6-15-3-425.3(3)^{\circ}$ and $14-15-3-234.8(3)^{\circ}$. The fused ring system leads to large distortions in bond angles and bond lengths.

Extracts from Helenium amarum (bitterweed) of the plant family Compositae were found to have cytotoxic properties in vitro (KB cell cultures derived from human carcinoma of the nasopharynx) and antitumor activity in vivo (P 388 Lympholytic leukemia in mice)*

Phytochemical investigation of the leaves of the plant resulted in the isolation of a number of sesquiterpene lactones.** The cytotoxicity of sesquiterpene lactones and their structureactivity relationships were investigated by Kupchan et al..$^{2}$ and a mechanism for inhibition of cancer growth by the sesquiterpenes tenulin,

* Screening of the extracts was carried out through the National Cancer Institute, Bethesda, Maryland, U.S.A.

** The isolation of heleniamarin and other constituents from $H$. amarum will be reported elsewhere. 
helenalin and other related sesquiterpenes was proposed by Hall et al.s

The spectroscopic data obtained for heleniamarin (see EXPERIMENTAL) indicated that this compound must belong to the pseudoguaianolide group of sesquiterpenes, of which several members earlier have been isolated from bitterweed. ${ }^{1}$ However, the complexity of the compound precluded a structure analysis by standard methods and an X-ray crystallographic structure determination was, therefore, carried out. Although a number of crystallographic structure determinations of these sesquiterpenes have been carried out (bromohelenalin, ${ }^{4}$ bromo isotenulin, ${ }^{5}$ bromomexicanin- $E^{6}$ ), a structure of heleniamarin will also have a wider interest other than the pure analytical determination of the compound composition.

\section{EXPERIMENTAL}

Heleniamarin, $\mathrm{C}_{17} \mathrm{H}_{22} \mathrm{O}_{5}$, was crystallized from diethyl ether, m.p. $151-153^{\circ} \mathrm{C},[\alpha]_{\mathrm{D}}{ }^{21}$ $+58.5^{\circ}\left(c 0.25, \mathrm{CHCl}_{3}\right)$. The IR spectrum showed bands at $v_{\max }(\mathrm{KBr}) 1770$ and 1755 (sh) $\mathrm{cm}^{-1}$ and the ${ }^{1} \mathrm{H}$ NMR showed signals for three methyl groups $(\delta 1.1-1.28)$, one methyl on oxygenated carbon at $\delta 1.50(\mathrm{~s}, 3 \mathrm{H})$, two triplets $(J=2 \mathrm{~Hz})$ at $\delta 2.82$ and 2.97 each for one proton, one exchangeable proton at $\delta \mathbf{3 . 6}$ (s), one proton doublet $(J=6.5 \mathrm{~Hz})$ at $\delta 4.07$, a multiplet at $\delta 5.03$ and a broad multiplet for one olefinic proton at $\delta \mathbf{5 . 7 8}$.

Oscillation and Weissenberg diagrams revealed monoclinic symmetry with all reflections $0 k 0$ systematically absent for $k=2 n+1$. The compound is optically active, which means that the space group is uniquely defined as $P 2_{1}$. The cell volume indicated two molecules in the unit cell.

The diagrams showed relatively large thermal dampening, and it was, therefore, decided to collect data at low temperature. A platy crystal of approximate dimensions $0.4 \times 0.2 \times 0.1 \mathrm{~mm}$ was mounted on a computer-controlled Syntex Pl four-circle diffractometer with a scintillation detector which is equipped with a modified Enraf-Nonius liquid nitrogen cooling device and graphite-monochromatized $\mathrm{MoK} \alpha$ radiation. Cell constants were determined by a leastsquares treatment of the angular coordinates of ten symmetry-independent reflections with $2 \theta$. values between 24 and $40^{\circ}$. The temperature at crystal site was $-165^{\circ} \mathrm{C}$.

Three-dimensional intensity data were recorded using the $\theta-2 \theta$ scanning mode with scan speed variable from 3 to $12^{\circ} \mathrm{min}^{-1}$, depending on the peak intensity of the reflection. The scan area was from $\left[2 \theta\left(\alpha_{1}\right)-0.9^{\circ}\right]$ to $\left[2 \theta\left(\alpha_{2}\right)+\right.$ $\left.0.9^{\circ}\right]$ and background counting time was equal to 0.7 times the scan time. The variations in the intensities of three check reflections which were remeasured after every sixty reflections were random, accordingly no corrections were applied to the intensity data for these variations.

The estimated standard deviations were taken as the square root of the total counts with a $2 \%$ addition of the net intensity for experimental uncertainties. Of the 2325 reflections measured $\left(2 \theta_{\max }=60^{\circ}\right)$, the 1900 which had intensities larger than twice their standard deviations, were regarded as observed and the remaining were excluded from the refinements. The intensities were corrected for Lorentz and polarization effects assuming the monochromator to be half perfect in the correction for polarization. The computer program used, as well as programs subsequently employed, is part of a local (Oslo) assembly of computer programs for CYBER-74 which is described in Ref. 7.

The atomic scattering factors used were those of Doyle and Turner ${ }^{8}$ for oxygen and carbon, and of Stewart et al..$^{2}$ for hydrogen.

\section{CRYSTAL DATA}

2a,4a,5,6,8,9a,9b,9c-Octahydro-2-hydroxy2,2a,6,9a-tetramethyl-2H-1,4-dioxadicyclopent[cd,f]azulene-3,9-dione (heleniamarin), $\mathrm{C}_{17} \mathrm{H}_{22} \mathrm{O}_{5}$, m.p. $151-153{ }^{\circ} \mathrm{C}, M=306.36 \mathrm{amu}$, space group $P 2_{1}$, cell dimensions at $-165^{\circ} \mathrm{C}: a=8.843(8)$ $\AA, b=7.991(7) \AA, c=10.938(10) \AA, \beta=96.41^{\circ}(7)$, $V=768.1(12) \AA^{3}, Z=2, D_{\text {calc }}=1.324 \mathrm{~g} \mathrm{~cm}^{-3}$, $F(000)=328$.

\section{STRUCTURE DETERMINATION}

The phase problem could not be solved by the standard MULTAN program assembly. ${ }^{10}$ Starting phases were, therefore, generated by the use of magic integers.11 In the resulting $E$-map from the statistically best solution of the run with starting phases generated by the use of the four integers $2,3,7$ and 13, 22 out of the 23 highest peaks could be pieced together to a chemically reasonable structure taking into consideration the known molecular formula, $\mathrm{C}_{17} \mathrm{H}_{22} \mathrm{O}_{5}$. The results from a least-squares refinement treating these 22 atoms as carbon atoms with isotropic temperature factors, clearly showed which of these are oxygen atoms.

The structure model was refined to a conventional $R\left(R=\sum\left|K F_{\text {obs }}-\right| F_{\text {calc }} \mid / \sum K F_{\text {obs }}\right.$, where $K$ is the scale factor) of 0.10 . At this point anisotropic thermal parameters were introduced for all the 22 nonhydrogen atoms. 
Table 1. Fractional atomic coordinates and thermal parameters with estimated standard deviations. The anisotropic temperature factor is given by: $\exp \left[-2 \pi^{2}\left\{U_{11}\left(a^{*} h\right)^{2}+U_{22}\left(b^{*} k\right)^{2}+U_{83}\left(c^{*} l\right)^{2}+\right.\right.$ $\left.\left.2 U_{12}\left(a^{*} b^{*} h k\right)+2 U_{13}\left(a^{*} c^{*} h l\right)+2 U_{23}\left(b^{*} c^{*} k l\right)\right\}\right]$.

\begin{tabular}{|c|c|c|c|c|c|c|c|c|c|}
\hline ATON & $x$ & $r$ & $z$ & USI & v22 & U33 & U12 & U13 & U23 \\
\hline 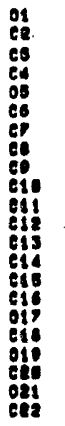 & 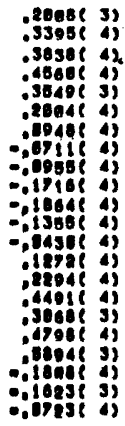 & 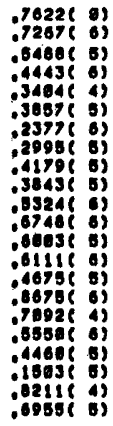 & 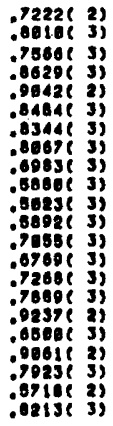 & 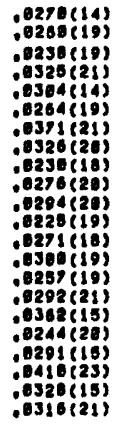 & 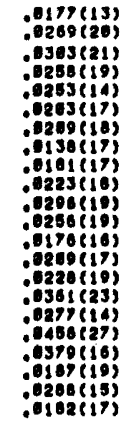 & 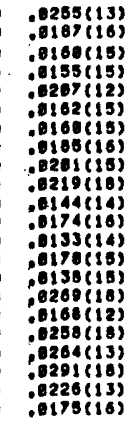 & 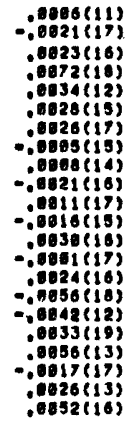 & 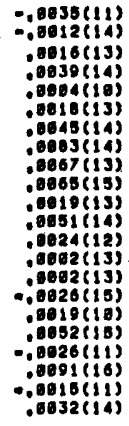 & 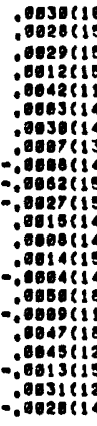 \\
\hline APOM & $x$ & $\gamma$ & 2 & - & ATOA & $x$ & $r$ & 2 & 0 \\
\hline 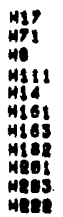 & 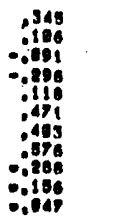 & 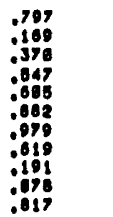 & $\begin{array}{l}.987 \\
.912 \\
.881 \\
.464 \\
.804 \\
796 \\
.814 \\
.675 \\
.777 \\
924 \\
919\end{array}$ & $\begin{array}{l}2,0 \\
1.0 \\
1.7 \\
1.0 \\
1.8 \\
2,8 \\
2,0 \\
2.0 \\
2,3 \\
2,3 \\
1.0\end{array}$ & 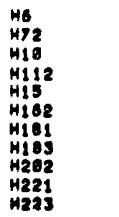 & $\begin{array}{r}.147 \\
.121 \\
-.215 \\
-.129 \\
.211 \\
.547 \\
.596 \\
-481 \\
-171 \\
-.182 \\
-.007\end{array}$ & $\begin{array}{l}.483 \\
.167 \\
.271 \\
.520 \\
.380 \\
.852 \\
.439 \\
.813 \\
.883 \\
.885 \\
.049\end{array}$ & $\begin{array}{l}.084 \\
.768 \\
.867 \\
.434 \\
.682 \\
.842 \\
.624 \\
.877 \\
.871 \\
.837 \\
.898\end{array}$ & $\begin{array}{l}1.5 \\
1.8 \\
1.8 \\
1.8 \\
1.8 \\
2.8 \\
2.2 \\
2.02 \\
2.3 \\
1.0 \\
1.0\end{array}$ \\
\hline
\end{tabular}

Table 2. Selected torsional angles $\left({ }^{\circ}\right)$. The angles are positive in a righthand screw.

Angle

$\left({ }^{\circ}\right)$
Angle

$\mathrm{Cl4}-\mathrm{O} 1-\mathrm{C} 2-\mathrm{Ol} 7$

$\mathrm{O} 1-\mathrm{C} 2-\mathrm{C} 3-\mathrm{C} 15$

$\mathrm{O} 17-\mathrm{C} 2-\mathrm{C} 3-\mathrm{C} 15$

$\mathrm{C} 15-\mathrm{C} 3-\mathrm{C} 4-\mathrm{O} 5$

$\mathrm{C} 4-\mathrm{O} 5-\mathrm{C} 6-\mathrm{C} 7$

$\mathrm{O} 5-\mathrm{C} 6-\mathrm{C} 7-\mathrm{C} 8$

C6-C7-C8-C9

C7-C8-C9-C10

$\mathrm{C} 8-\mathrm{C} 9-\mathrm{C} 10-\mathrm{Cl1}$

$\mathrm{C} 9-\mathrm{C} 10-\mathrm{C} 11-\mathrm{C} 12$

$\mathrm{C} 10-\mathrm{C} 11-\mathrm{C} 12-\mathrm{C} 21$

$\mathrm{Cl1}-\mathrm{Cl2}-\mathrm{C} 13-\mathrm{Cl} 4$

$\mathrm{Cl2}-\mathrm{Cl3}-\mathrm{C} 9-\mathrm{ClO}$

$\mathrm{Cl} 4-\mathrm{Cl3}-\mathrm{C} 9-\mathrm{C} 10$

$\mathrm{C} 9-\mathrm{Cl3}-\mathrm{Cl} 4-\mathrm{Cl} 5$

C12-C13-C14-C15

$\mathrm{C15}-\mathrm{C} 14-\mathrm{O} 1-\mathrm{C2}$

$\mathrm{C13}-\mathrm{C14}-\mathrm{C15}-\mathrm{C} 6$

$\mathrm{O} 1-\mathrm{Cl} 4-\mathrm{Cl} 5-\mathrm{C} 6$

$\mathrm{C14-C15- \textrm {C } 6 - \mathrm { O } 5}$

C3-Cl5-C6-O5

$\mathrm{Cl4}-\mathrm{Cl} 5-\mathrm{C3}-\mathrm{C} 4$

C6-Cl5-C3-C4 $\left(^{\circ}\right)$
$-89.3(3)$

$-36.0(3)$

$79.3(3)$

$-9.8(4)$

$150.6(3)$

$166.0(2)$

53.5(4)

$109.4(4)$

175.5(3)

$-12.0(4)$

$-160.4(4)$

93.9(3)

12.5(4)

$-97.1(3)$

$-37.2(4)$

$-144.7(3)$

$-2.2(3)$

- 33.3(4)

$-146.0(3)$

$-31.7(3)$

$150.0(3)$

25.3(3)

Acta Chem. Scand. B 32 (1978) No. 2 
Full-matrix least-squares refinement of all positional and thermal parameters reduced $R$ to 0.085 . The quantity minimized was $\sum w$ ( $F_{\text {obs }}-$ $\left.(1 / K)\left|F_{\text {calc }}\right|\right)^{2}$ with $w=1 / \sigma^{2}$ ( $\left.F_{\text {obs }}\right)$, and origo along the $b$-axis was held by keeping the $y$ positional parameter of $\mathrm{Ol}$ fixed. The 22 hydrogen atoms were then placed in calculated positions using a $\mathrm{C}-\mathrm{H}$ and $\mathrm{O}-\mathrm{H}$ distance of 1.0 $\AA$, and included in the structure factor calculations with estimated isotropic thermal parameters. The distances indicated one intermolecular hydrogen bond (017-019) and the hydrogen atom bonded to 017 (H.17) was placed accordingly. Full-matrix least-squares refinement of all parameters in volving the heavy atoms resulted in an $R$ of 0.057 and an $R_{\mathrm{w}}$ of $0.052\left(R_{\mathrm{w}}=\left[\sum w\left(K F_{\text {obs }}-\right.\right.\right.$
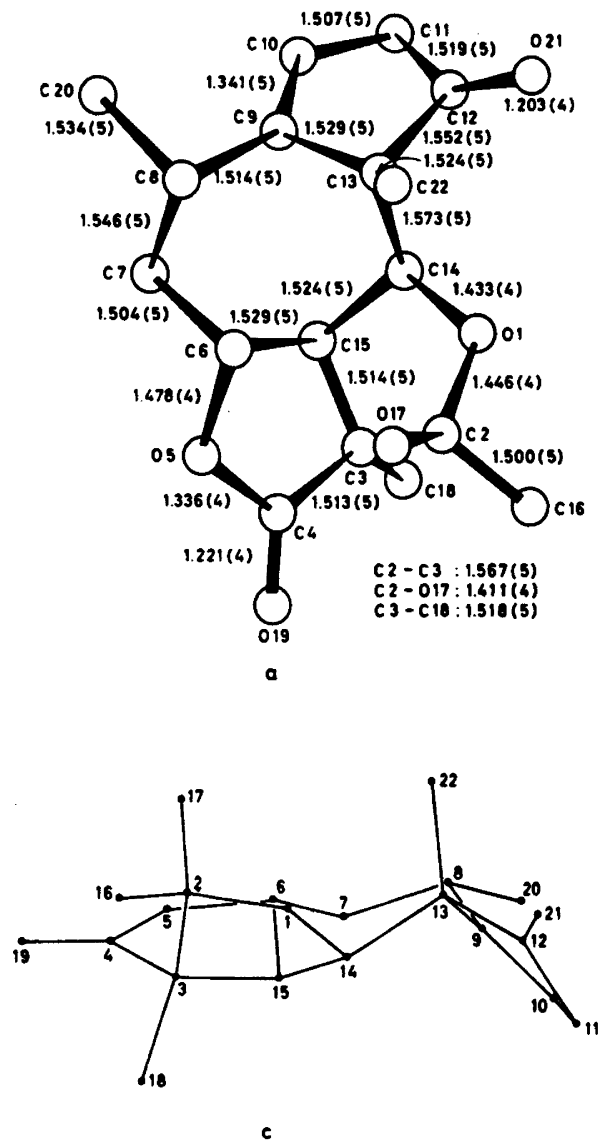

$\left.\left.\left.\left|F_{\text {calc }}\right|\right)^{2} / \sum w F_{\text {obs }^{2}}\right]^{\frac{1}{3}}\right)$. A difference Fourier synthesis revealed only spurious peaks of maximum densities 0.3 e $\AA^{-3}$. Final atomic parameters are given in Table 1. A list of observed and calculated structure factors is available from the authors upon request. (May also be obtained from: Department of Chemistry, University of Oslo, Oslo 3, Norway.)

Standard deviations in molecular parameters were calculated from the correlation matrix ignoring standard deviations in cell parameters.

\section{DISCUSSION}

The structure of heleniamarin (1) is closely related to that of tenulin (2) which previously has been isolated from bitterweed, the only
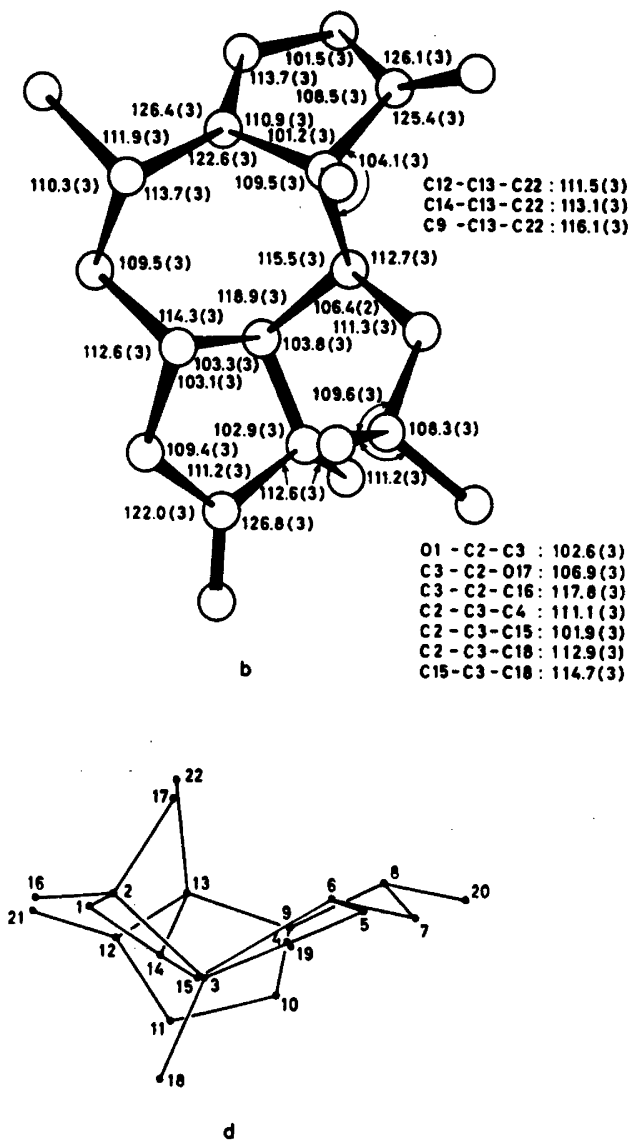

Fig. 1. The molecule as seen down in the least-squares plane of all 22 heavy atoms (a and b). Bond lengths $(\AA)$ and bond angles $\left({ }^{\circ}\right)$ with estimated standard deviations are listed in $a$ and b, respectively. Two views of the molecule as seen in the plane $90^{\circ}$ apart are given in $\mathrm{c}$ and $\mathrm{d}$. 
difference being the position of the double bond in the cyclopentene ring. Bond lengths and bond angles obtained for heleniamarin are listed in Fig. 1, where also the atomic numbering is given. Selected torsional angles are listed in Table 2.

The central seven-membered ring has a chair conformation, see Fig. 1c, with the five central atoms in a plane. Deviations from a leastsquares plane through $\mathrm{C7}, \mathrm{C8}, \mathrm{C} 13$ and $\mathrm{C14}$ are: C7: $0.059 \AA$, C8: $-0.076 \AA$, C13: $0.076 \AA$, C14: $-0.058 \AA, \mathrm{C} 15:-0.049 \AA, \mathrm{C6}$ : $0.795 \AA$ and C9: $-0.693 \AA$. The planes through $\mathrm{C} 6, \mathrm{C} 7$ and $\mathrm{C} 15$ and $\mathrm{C} 8, \mathrm{C} 9, \mathrm{Cl} 3$ form angles of $73.9^{\circ}$ and $71.6^{\circ}$, respectively, with the central plane. Both the furan and cyclopentene ring have envelope conformations with $\mathrm{C} 3$ and $\mathrm{C} 12$, respectively, out of the ring planes. Deviations from a least-squares plane through $01, \mathrm{C} 2$, $\mathrm{C14}$ and $\mathrm{C} 15$ are: 01 : $-0.010 \AA, \mathrm{C} 2: 0.008 \AA$, C14: $0.013 \AA, C 15:-0.008 \AA$ and C3: $-0.578 \AA$, and the torsional angles $\mathrm{C} 14-\mathrm{O} 1-\mathrm{C} 2-\mathrm{C} 3$ and $\mathrm{O} 1-\mathrm{C} 14-\mathrm{Cl} 15-\mathrm{C} 3$ are $24.0(3)$ and $-21.5(3)^{\circ}$, respectively. Deviations from a least-squares plane through $\mathrm{C} 9, \mathrm{Cl}, \mathrm{C11}$ and $\mathrm{Cl} 3$ are: $\mathrm{C} 9$ : $0.003 \AA, \mathrm{C} 10$ : $-0.003 \AA, \mathrm{C} 11: 0.001 \AA, \mathrm{C13}$ : $-0.001 \AA, \mathrm{C} 12: 0.319 \AA$ and C8: $0.095 \AA$, and the torsional angles $\mathrm{C} 9-\mathrm{C} 10-\mathrm{C} 11-\mathrm{C} 12$ and $\mathrm{C} 12-\mathrm{C} 13-\mathrm{C} 9-\mathrm{C} 10$ are $-12.0(4)$ and $12.5(4)^{\circ}$, respectively. The lactone ring has a twist conformation with $\mathrm{C} 60.266 \AA$ above and $\mathrm{C} 15$ $0.250 \AA$ below the plane through the other three ring atoms. The torsional angles $\mathrm{C3}-\mathrm{C} 15-\mathrm{C} 6-\mathrm{O} 5, \quad \mathrm{C} 15-\mathrm{C} 3-\mathrm{C} 4-\mathrm{O} 5$ and $\mathrm{C} 3-\mathrm{C} 4-\mathrm{O} 5-\mathrm{C} 6$ are $-31.7(3),-9.8(4)$ and $-11.0(4)^{\circ}$, respectively.

The lactone and furan rings form a $V$-shape around the central C3-C15 bond (see Fig. 1d), the torsional angles $\mathrm{C} 14-\mathrm{C} 15-\mathrm{C} 3-\mathrm{C} 4$ and $\mathrm{C} 6-\mathrm{C} 15-\mathrm{C} 3-\mathrm{C} 2$ are $150.0(3)$ and $-89.9(3)^{\circ}$, respectively with $\mathrm{C} 6-\mathrm{Cl} 5-\mathrm{C} 3-\mathrm{C} 425.3(3)^{\circ}$ and $\mathrm{Cl4}-\mathrm{C} 15-\mathrm{C} 3-\mathrm{C} 234.8(3)^{\circ}$. The major plane of the cyclopentene ring forms an extension to the chair conformation of the sevenmembered ring.

The fused ring system leads to large distortions in bond angles (see Fig. 1b). The C6-C15-C14 angle has been opened to $118.9(3)^{\circ}$, while the $\mathrm{C} 3-\mathrm{C} 15-\mathrm{Cl} 6$ and $\mathrm{C} 3-\mathrm{Cl} 5-\mathrm{Cl} 14$ angles are 103.3(3) and 103.8(3) respectively. The closing of the two angles $\mathrm{C} 2-\mathrm{C} 3-\mathrm{Cl} 5$ and $\mathrm{C} 4-\mathrm{C} 3-\mathrm{Cl5}$ [101.9(3) and $102.9(3)^{\circ}$, respectively] leads to an opening of the three exocyclic angles involving C18. Similarly the small value of the C10-C9-C13 angle gives a large exocyclic $\mathrm{C} 8-\mathrm{C} 9-\mathrm{C} 10$ angle. Other distortions are also apparent.

The stressed ring system also appears to distort the bonding, as has been found in other fused ring compounds. ${ }^{12}$ The $\mathrm{C} 2-\mathrm{C} 3$ and $\mathrm{C} 13-\mathrm{C} 14$ bonds of $1.567(5)$ and 1.573(5) $\AA$, respectively, are significantly larger than the normal $\mathrm{C}\left(s p^{3}\right)-\mathrm{C}\left(s p^{3}\right)$ bond of $1.536 \AA$, and further the $\mathrm{C}\left(s p^{2}\right)-\mathrm{C}\left(s p^{3}\right)$ bond $\mathrm{C} 12-\mathrm{C} 13$ of $1.552(5) \AA$ is significantly longer than the standard value of $1.527 \AA$. On the other hand, the $\mathrm{C} 3-\mathrm{C} 15$ and $\mathrm{C} 6-\mathrm{C} 7$ bonds [1.514(5) and 1.504(5) $\AA$, respectively] are shortened. Similarly the $\mathrm{C} 2-\mathrm{C} 16[1.500(5) \AA]$ and $\mathrm{C} 3-\mathrm{C} 18$ $\left[\begin{array}{ll}1.518(5) & \AA\end{array}\right]$ bonds are short, part of the apparent shortening of these exocyclic bonds may be due to the influence of thermal vibration effects on the positional parameters. The C4-O5 bond of 1.336(4) $\AA$ is short, the double character is 0.44 , and the $\mathrm{O} 5-\mathrm{C} 6$ bond $[1.478(4) \AA]$ is very long. Part of the distortion in this part of the molecule may be due to the inter-molecular hydrogen bond from $\mathrm{Ol7}$ to 019 [in position: $\mathrm{I}-x, 0.5-y, 2-z ; 0-\mathrm{O}$ distance: 2.740(4) $\AA$ ], which leads to a lengthening of the $\mathrm{C} 4-\mathrm{O} 19$ bond. ${ }^{13}$

Acknowledgement. This research was sup. ported in part by the Research Institute of Pharmaceutical Sciences, School of Pharmacy, University of Mississippi, University, Mississippi 38677.

\section{REFERENCES}

1. Herz, W., Rohde, W. A., Rabindran, K., Jayaraman, P. and Viswanathan, N. J. Am. Chem. Soc. 84 (1962) 3857.

2. Kupchan, S. M., Eakin, M. A. and Thomas, A. M. J. Med. Chem. 14 (1971) 1147.

3. Hall, I. H., Lee, K. H., Mar, E. C., Starnes, C. O. and Waddell, T. G. J. Med. Chem. 20 (1977) 333.

4. Emerson, M. T., Caughlan, C. N. and Herz, W. Tetrahedron Lett. (1964) 621.

5. Rogers, D. and M.-ul-Haque. Proc. Chem. Soc. London (1963) 92.

6. M.-ul-Haque and Caughlan, C. N. J. Chem. Soc. $B$ (1967) 355.

7. Groth, P. Acta Chem. Scand. 27 (1973) 1837.

8. Doyle, P. A. and Turner, P. S. Acta Crystallogr. A 24 (1968) 390.

9. Stewart, R. F., Davidson, E. R, and

Acta Chem. Scand. B 32 (1978) No. 2 
Simpson, W. T. J. Chem. Phys. 42 (1965) 3175.

10. Germain, G., Main, P. and Woolfson, M. M. Acta Crystallogr. A 27 (1971) 368.

11. Declercq, J. P., Germain, G. and Woolfson, M. M. Acta Crystallogr. A 31 (1975) 367.

12. Ottersen, T., Rømming, C. and Snyder, J. P. Acta Chem. Scand. B 30 (1976) 407.

13. Ottersen, T. Adv. Mol. Relaxation Processes 9 (1976) 105.

Received August 4, 1977. 